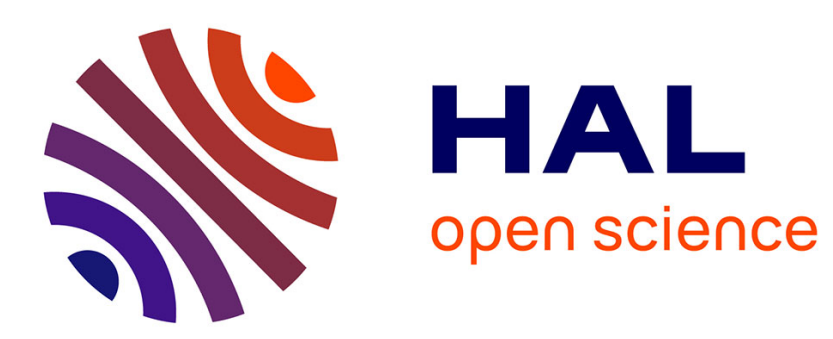

\title{
Application of Local Damage and Fracture Models to Notched Round Copper Bars
}

T. Pardoen, P. Delatte, J. Morhet, I. Doghri, R. Knockaert, F. Delannay

\section{To cite this version:}

T. Pardoen, P. Delatte, J. Morhet, I. Doghri, R. Knockaert, et al.. Application of Local Damage and Fracture Models to Notched Round Copper Bars. Journal de Physique IV Proceedings, 1996, 06 (C6), pp.C6-145-C6-153. 10.1051/jp4:1996614 . jpa-00254442

\section{HAL Id: jpa-00254442 https://hal.science/jpa-00254442}

Submitted on 1 Jan 1996

HAL is a multi-disciplinary open access archive for the deposit and dissemination of scientific research documents, whether they are published or not. The documents may come from teaching and research institutions in France or abroad, or from public or private research centers.
L'archive ouverte pluridisciplinaire HAL, est destinée au dépôt et à la diffusion de documents scientifiques de niveau recherche, publiés ou non, émanant des établissements d'enseignement et de recherche français ou étrangers, des laboratoires publics ou privés. 


\title{
Application of Local Damage and Fracture Models to Notched Round Copper Bars
}

\author{
T. Pardoen, P. Delatte*, J. Morhet*, I. Doghri*, R. Knockaert* and F. Delannay \\ Université Catholique de Louvain, Département des Sciences des Matériaux et Procédés, PCIM, 2 Place \\ Sainte-Barbe, 1348 Louvain-la-Neuve, Belgium \\ * Université Catholique de Louvain, Département de Mécanique, MEMA, 4 avenue G. Lemaître, \\ 1348 Louvain-la-Neuve, Belgium
}

\begin{abstract}
The Rice \& Tracey, damage work, and Lemaître \& Chaboche models were investigated on cylindrical notched extruded copper bars. The values of the two constant factors appearing in the expression of the void growth rate in the Rice \& Tracey model were reevaluated by combining experiments (porosity measurements and tensile tests) and numerical computations of uniaxial tensile tests and of tensile tests on notched round bars. The values of the critical void growth rates (Beremin approach) and critical damage works were found to be independent on triaxiality. The application of the Lemaitre \& Chaboche model allows to predict the softening appearing at initiation for lower triaxialities. Difficulties were encountered to physically identify the parameters of the model.
\end{abstract}

\section{INTRODUCTION}

This paper is devoted to a critical assessment of the application of the local approach methodology for the prediction of the initiation of fracture in cylindrical, notched, copper specimens. The materials investigated are extruded copper bars with two different initial strain-hardening levels. This material has, to our knowledge, never been studied by damage modelling; its damaged behaviour is, however, very "academic" and easy to analyse. Beside this, the effect of strain-hardening on the damage evolution and modelling is an issue about which only few results exist.

Previous work on the measurement of the fracture toughness of axisymmetrical copper bars in terms of a critical $J$ integral or a critical crack tip opening displacement has demonstrated the absence of $\mathrm{J}$ dominance in such bars because of the too extensive yielding [1]. To overcome this problem and to be able to predict the initiation of ductile cracking, three local approach models were investigated : the Beremin approach $[2,3]$ and the damage work model [4] which are uncoupled models based on the Rice \& Tracey [5] model for the growth of the cavities and the Lemaitre \& Chaboche model [6].

One of the most important challenges in the field of damage modelling is to reconcile physics and numerics. In particular, in the case of the Rice and Tracey model, the material microstructural properties can be taken into account [7] by an experimental determination of the constants appearing in the void growth rate relation. Porosity measurements and metallographical work combined with image analysis are always difficult and time-consuming, but necessary in order to account properly for the microstructure and flow properties of the material. In this work, a methodology was followed to measure the evolution of density and to correct the latter with the help of finite element simulation. Two important characteristic features of the damage behaviour of the material emerge : a lower bound for the constant appearing in the Rice \& Tracey model and a value for the critical void volume fraction at initiation, $f_{c}$. The relation expressing the evolution of porosity with deformation can be used to identify parameters of the Lemaitre \& Chaboche model. Having measured the initial inclusion volume fraction, $\mathrm{f}_{0}$, and knowing the value of $\mathrm{f}_{\mathfrak{c}}$, we possess also the physical parameters needed for Gurson-Tvergaard type simulations. 


\section{MATERIAL PROPERTIES AND EXPERIMENTAL PROCEDURE}

\subsection{Material}

The material consists of extruded, $99.7 \%$ pure copper bars of $10 \mathrm{~mm}$ diameter. The grains are elongated in the extrusion direction and present some degree of texture (111). The copper matrix contains a fine dispersion of spherical inclusions of $0.8 \mu \mathrm{m}$ average diameter size (average of the dimensions of about 300 inclusions) which are the sites of nucleation of the cavities which grow until coalescence. The volume fraction of inclusions responsible for the nucleation of voids was estimated at 0.002 from the number of inclusions measured per unit area and their average diameter size. Half of the bars were annealed for one hour at $300^{\circ} \mathrm{C}$ in order to bring about large ductility due to recrystallization and thus to change the initial strain-hardening exponent without perturbing the microstructure (inclusion distribution,...); only the grain size undergoes $20 \%$ growth. The bars will be called CuAR when in the as-received state and $\mathrm{CuA}$ when in the annealed state.

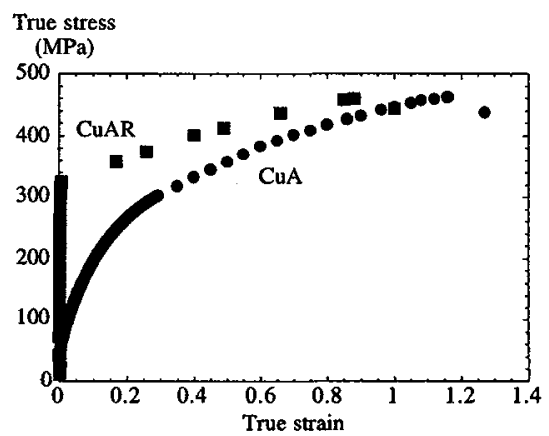

Figure 1: True stress-strain curves

A Young's modulus of $121 \mathrm{GPa}$ was measured using the method of the self vibration frequency of the bars. The constitutive laws were determined by uniaxial tensile testing of bars CuAR and CuA. To obtain the true stress in the minimum section after necking, use was made of the Bridgman relation [8]. Fig. 1 shows the true stress-true strain curves of $\mathrm{CuAR}$ and $\mathrm{CuA}$. These curves can be fitted by using successively two different power-laws :

$$
\sigma=\mathrm{K}_{1} \varepsilon^{\mathrm{n}_{1}} \text { for } \varepsilon<20 \% \text { and } \sigma=\mathrm{K}_{2} \varepsilon^{\mathrm{n}_{2}} \text { for } \varepsilon>20 \%
$$

The need of two successive power laws has been well assessed in the literature [9]. The main mechanical parameters are listed in Table 1.

Table 1 Main mechanical characteristics of the extruded copper bars : Young's modulus, E; yield stress, $\sigma_{0.2 \%}$; strain at necking, $\varepsilon_{t s}$; stress at necking, $\sigma_{t s}$; strain at cavity coalescence (when a drop appears on the curves), $\varepsilon_{\mathrm{f}}$, stress at coalescence, $\sigma_{f}$, parameters $K_{i}$ and $n_{i}$ of the power laws (1).

\begin{tabular}{ccccccccc}
\hline & $\begin{array}{c}\mathrm{E} \\
\sigma_{0.2 \%}\end{array}$ & $\varepsilon_{\mathrm{ts}}$ & $\sigma_{\mathrm{ts}}$ & $\varepsilon_{\mathrm{f}}$ & $\sigma_{\mathrm{f}}$ & $\mathrm{K}_{1} / \mathrm{K}_{2}$ & $\mathrm{n}_{1} / \mathrm{n}_{2}$ \\
& $(\mathrm{GPa})$ & $(\mathrm{MPa})$ & $(\%)$ & $(\mathrm{MPa})$ & $(\%)$ & $(\mathrm{MPa})$ & $(\mathrm{MPa})$ & \\
\hline $\mathrm{CuAR}$ & 121 & 312 & 0.8 & 325 & 88 & 452 & $381 / 470$ & $.032 / .17$ \\
$\mathrm{CuA}$ & 121 & 45 & 29 & 302 & 118 & 470 & $517 / 450$ & .431 .32 \\
\hline
\end{tabular}




\subsection{Damage characterization}

Two methods were used to evaluate damage : the change of density and the change of Young's modulus. The measurement of the change of Young's modulus involved the machining of the tensile specimens after necking and the use of strain gages in the center of the neck. Due to the effect of strain induced texturing, softening effects due to damage were hidden by the stiffening effect due to texture development. In order to measure density, $d$, small sections of the centre of the neck were cut symmetrically in the middle of the tensile specimens. The average densities of these sections were calculated by the Archimedean method in xylene. Fig. 2 shows the evolution of the relative porosity, $\left(d_{0}-d\right) / d_{0}$, versus the equivalent strain, $d_{0}$ being the initial density. The damage begins nearly immediately. The critical relative densities at initiation of cracking are identical for CuAR and CuA. A subsequent heat treatment allowing recovery followed by density measurements has proven that the volume of dislocations was negligible. A simple model based on the Rice \& Tracey void growth rate shall allow to correct the density measurements in such a way as to determine a local density/strain law.

The Lemaitre and Chaboche model being based on the effect of damage on the change of Young's modulus, we have to convert the evolution of density into a corresponding Young's modulus evolution. For this purpose, and because no accepted theoretical model exists for this conversion, we have used the work of Dufailly [9] who also analysed the damage behaviour of copper (but with no textural effect) and determined the evolution of Young's modulus as a function of density.

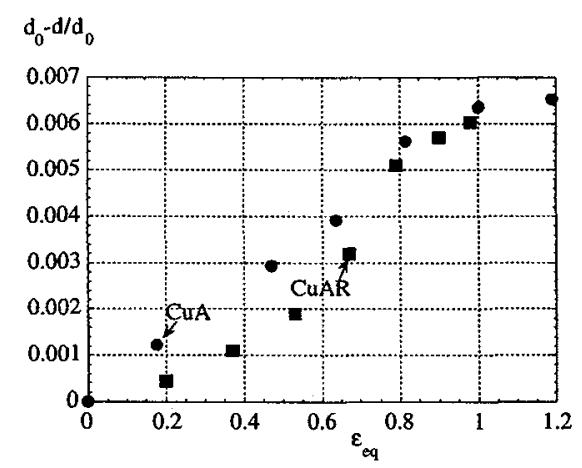

Figure 2 : Experimental strain dependence of the average relative porosity of a small volume cut in the neck of a tensile specimen.

\subsection{Tensile Tests on Notched Round Bars}

In order to study the evolution of the critical damage at coalescence as a function of the triaxiality, four specimen geometries were made by machining axisymmetrical notches of $1,2,4$ or $8 \mathrm{~mm}$ radii in the $10 \mathrm{~mm}$ diameter bars. A minimum of four tests were performed for each geometry on $\mathrm{CuAR}$ and $\mathrm{CuA}$. The tensile tests were performed at the constant speed of $0.5 \mathrm{~mm} / \mathrm{min}$. The reduction of diameter was measured by a radial extensometer. The tests were stopped just after the onset of coalescence to allow for metallographical studies of the centre of the neck.

\section{LOCAL APPROACH MODELS - FINITE ELEMENT SIMULATIONS}

\subsection{Rice \& Tracey Void Growth Model}

The Rice \& Tracey [5] model allows to calculate the growth of a spherical cavity in an infinite, rigid, perfectly plastic material subjected to an uniform remote strain field. The rate of growth expresses as

$$
\frac{\mathrm{dR}}{\mathrm{R}}=\alpha \exp \left(\frac{3 \sigma_{\mathrm{m}}}{2 \sigma_{\mathrm{eq}}}\right) \mathrm{d} \varepsilon_{\mathrm{eqp}}
$$


where $\mathrm{R}$ is the actual radius of the cavity, $\sigma_{\mathrm{m}}=\sigma_{\mathrm{ii}} / 3$ the average stress, $\varepsilon_{\text {eqp }}$ the equivalent plastic strain, and $\alpha$ a constant. To account for strain hardening, Beremin [3] has proposed to introduce the von Mises equivalent stress, $\sigma_{\mathrm{eq}}$, for the yield stress in the exponentional function. The $3 / 2$ value appearing on the exponential function is very well validated on different materials and will be also reassessed further in this paper. If this value is not found, it is probable that damage mechanism other than cavity growth induces the coalescence [10]. A value of $\alpha=0.283$ was predicted by Rice \& Tracey [5], but Huang [11] re-evaluated the model and obtained $\alpha=0.427$. In real materials, the stress and strain fields around the voids can interact and this explain why some authors [7] found different experimental values for $\alpha$. Hence, $\alpha$ does depend on $\mathrm{f}_{0}$, and cavity distribution, i.e. on the material microstructure. According to McClintock [12] and Beremin [3], a fracture criterion can be based on the Rice \& Tracey model : coalescence begins when a critical void growth is attained.

\subsection{Damage Work Model}

In the damage work model proposed by Chaouadi [4], the total energy, $\mathrm{W}_{\mathrm{d}}$, spent in deforming a material is equal to

$$
W_{d}=\int_{0}^{\varepsilon}\left(\sigma_{e q} d \varepsilon_{e q}+\sigma_{m} d \varepsilon_{i i}\right)
$$

The second term corresponds to the work spent for the growth of voids. Referring to the Rice \& Tracey model, $\mathrm{d} \varepsilon_{\mathrm{i} i} / 3=\mathrm{dR} / \mathrm{R}$, and neglecting the elastic work, the expression of the so-called "damage work" becomes

$$
\mathrm{W}_{\mathrm{d}}=\int_{0}^{\varepsilon}\left[1+3 \alpha \frac{\sigma_{\mathrm{m}}}{\sigma_{\mathrm{eq}}} \exp \left(\frac{3 \sigma_{\mathrm{m}}}{2 \sigma_{\mathrm{eq}}}\right)\right] \sigma_{\mathrm{eq}} \mathrm{d} \varepsilon_{\mathrm{eq}}
$$

This model is based on identical hypotheses and method of evaluation as the Rice \& Tracey model. It accounts more directly for the flow properties of the material. The associated fracture criterion is the attainment of a critical damage work, $\mathrm{W}_{\mathrm{dc}}$.

\subsection{Lemaître \& Chaboche Damage Model}

The Lemaître \& Chaboche model [6] deals in a coupled manner with elastoplasticity and damage. The evolution of damage is followed by a variable, called D. The definition of D is based on the effect of damage on the elastic properties :

$$
\mathrm{D}=1-\frac{\mathrm{E}}{\mathrm{E}_{0}}
$$

The basic equations of this model write

$$
\begin{aligned}
& \dot{\mathrm{D}}=\frac{\mathrm{Y}}{\mathrm{S}_{0}} \dot{\mathrm{p}} \geq 0 \quad \tilde{\sigma}=\frac{\sigma}{1-\mathrm{D}} \\
& \dot{\varepsilon_{\mathrm{eq}}}=\sqrt{\frac{2}{3} \dot{\varepsilon}_{\mathrm{p}} \dot{\varepsilon}_{\mathrm{p}}}, \mathrm{Y}=\frac{\left[\widetilde{\sigma}_{\mathrm{eq}}\right]^{2}}{2 \mathrm{E}_{0}} R_{v}, R_{\mathrm{v}}=\frac{2}{3}(1+v)+3(1-2 v)\left[\frac{\sigma_{\mathrm{m}}}{\sigma_{\mathrm{eq}}}\right]^{2}
\end{aligned}
$$

with $v$, Poisson's ratio, E, Young's modulus, $\mathrm{E}_{0}$, initial Young's modulus, $\mathrm{S}_{0}$ a constant to be identified. The experimental uniaxial damage evolution allows to obtain $\mathrm{S}_{0}$ numerically. 


\subsection{Finite Element Simulations}

Finite element simulations of notched specimens were performed using two different commercial codes : SYSTUS (Framasoft) and SPECTRUM (Centric Eng. Systems) [16]. The aim was to evaluate the reproductibility of the numerical models. The elastoplastic finite strain formulation is used in both cases. Identical element size $(222 \mu \mathrm{m})$ were chosen for the minimum sections in the notch. This element size was found sufficient for convergence. The results being nearly equivalent for the two codes, no mention of the origin of the results will be made.

\subsection{Model for the correction of the porosity measurements}

A simple model based on the Rice \& Tracey model can be used to correct our density measurements. The hypothesis is that the porosity evolves linearly with the plastic strain increment and with the exponential of the triaxiality multiplied by $3 / 2$. The porosity can be written as a function of the void growth rate as

$$
\left(\frac{\mathrm{d}_{0}-\mathrm{d}}{\mathrm{d}_{0}}\right)_{\text {local }}=\mathrm{f}_{0}\left(\left(\frac{\mathrm{R}}{\mathrm{R}_{0}}\right)^{3}-1\right)
$$

with $f_{0}$, the initial void volume fraction which is taken to be equal to the inclusion volume fraction. (In this way, we obtain a lower bound for the ductility because we take into account the maximal value for $f_{0}$ [13] considering that the distribution of inclusions is observed to be nearly homogeneus and that no cluster of inclusions could influence $f_{0}$ ). Thus, integrating the Rice and Tracey model, we obtain

$$
\left(\frac{\mathrm{d}_{0}-\mathrm{d}}{\mathrm{d}_{0}}\right)_{\text {local }}=\mathrm{f}_{0}\left(\left(\exp \alpha \int_{0}^{\varepsilon} \exp \left(\frac{3 \sigma_{\mathrm{m}}}{2 \sigma_{\mathrm{eq}}}\right) \mathrm{d} \varepsilon\right)^{3}-1\right)
$$

Finally, by averaging the local porosity value in the volume of the neck, $V$, used to measure the density, we obtain an equation with the only unknown $\alpha$ :

$$
\left(\frac{\mathrm{d}_{0}-\mathrm{d}}{\mathrm{d}_{0}}\right)_{\text {mean }}=\frac{\int_{\mathrm{v}} \mathrm{f}_{0}\left(\left(\exp \alpha \int_{0}^{\varepsilon} \exp \left(\frac{3 \sigma_{\mathrm{m}}}{2 \sigma_{\mathrm{eq}}}\right) \mathrm{d \varepsilon}\right)^{3}-1\right) \mathrm{dV}}{\mathrm{V}}
$$

The triaxiality ratio and the plastic strain increment are derived from finite element simulation of the tensile test. One difficulty is to use the right initial volume corresponding after strain to the volume cut in the neck section. Equation (11) can be solved for different experimental density values at different levels of deformation. If the same value for $\alpha$ is obtained, the consistency of the model is confirmed.

\section{RESULTS}

\subsection{Numerical results for the uniaxial tensile tests}

Figure $3 \mathrm{a}$ compares to the experiment, for CuAR, the macroscopic results of the finite element simulation of the tensile test in terms of the average stress, P/S ( $S$ being the actual surface of the minimum section) versus equivalent strain. Following the model described in 3.5., the $\alpha$ factor is evaluated at different steps with equation (11). The values are nearly constant and equal to 0.48 ( + or 0.01 ) at every step. With equation (10), it is then possible to correct our density measurements and in particular, we obtain a value $\mathrm{f}_{c}=0.02$ for the critical void volume fraction at coalescence. 


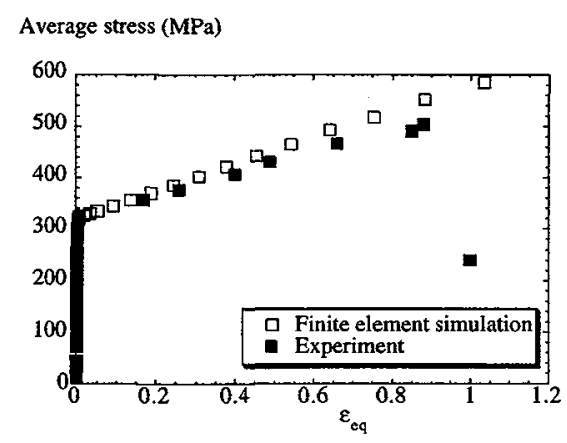

(a)

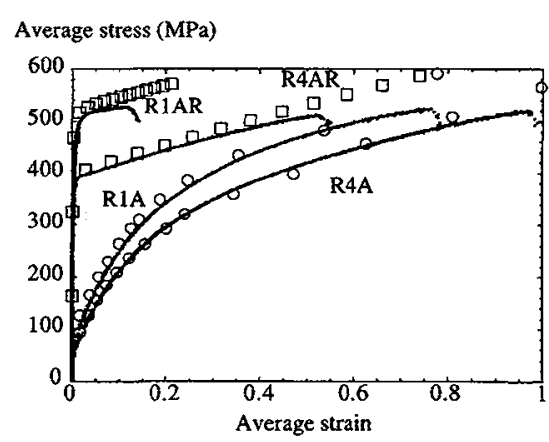

(b)

Figure 3 : a) uniaxial average stress-equivalent strain curves; experimental and elastoplastic finite element results; b) average stress-average strain curves for the notched round bars (CuAR-R1, CuAR-R4, CuA-R1 and CuA-R4); experiment and elastoplastic finite element results

\subsection{Tensile Tests on the Notched Cylindrical Bars}

A few results are gathered in Fig. $3 \mathrm{~b}$ which presents the evolution of the average stress versus equivalent strain in the minimum section for initial radii of curvature equal to 1 and 4 (R1 and R4) and for CuAR and $\mathrm{CuA}$. The strain at coalescence is detected by a marked shoulder in the curves. Metallographic study confirmed this fact and showed that coalescence starts in the centre of the minimum section.

\subsection{Numerical Results for the notched teinsile tests}

4.3.1Elastoplastic Simulations : Fig.3b demonstrates that the finite element results (open symbols) reproduce the experimental average stress versus equivalent strain curves to a good accuracy until crack initiation. Both experimental and numerical results show that damage is maximum in the center of the bars for all specimen geometries. The strains at coalescence, $\varepsilon_{c}$, the critical void growth rates, $R_{c} / R_{0}$ and the critical damage works, $W_{d c}$ were thus evaluated at the center of the bars (with $\alpha=0.427$ and nucleation at zero strain). Fig. 4 shows the evolution of $\ln \left(\varepsilon_{\text {eqc }}\right)$ versus average triaxiality ratio. Fig. 5a and $5 b$ gives the evolution of $R_{c} / R_{0}$ and $W_{d c}$ with the average triaxiality ratio for CuAR and $C u A$. For each particular result, we give the values for different experimental values of $\varepsilon_{\text {eqc }}$ in order to show the experimental dispersion at the onset of coalescence.

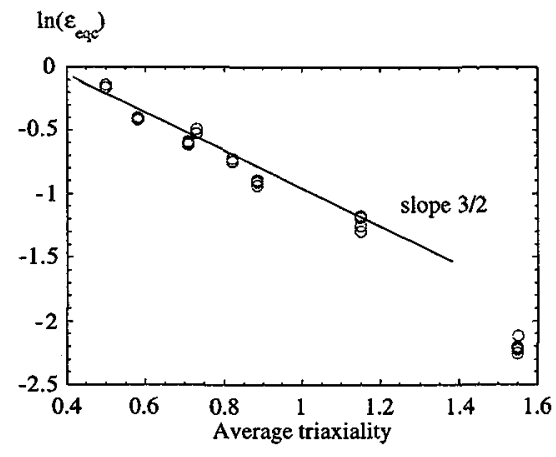

Figure $4: \ln \left(\varepsilon_{\text {eqc }}\right)$ versus average triaxiality for $\mathrm{CuAR}$ and $\mathrm{CuA}$ at coalescence 


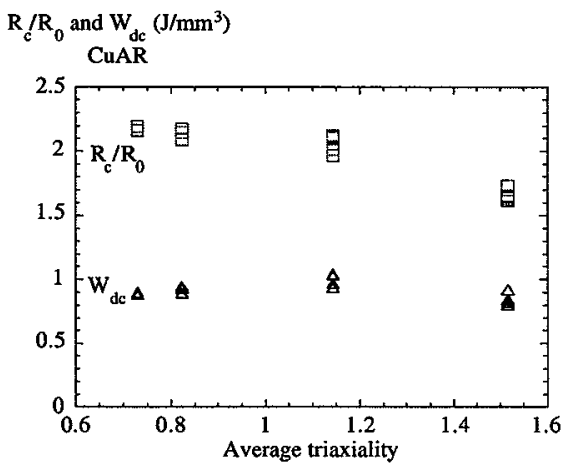

(a)

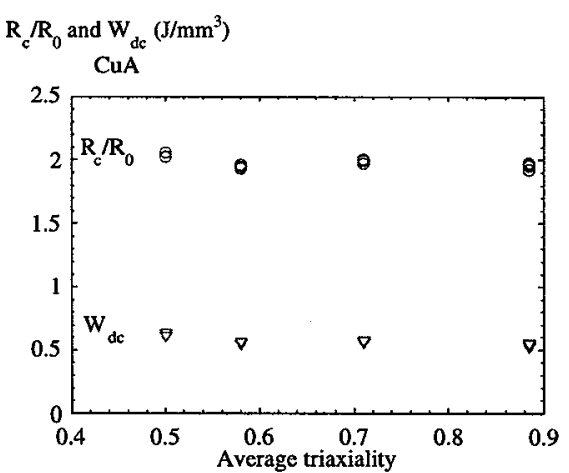

(b)

Figure 5 : Critical void growth rates and damage works a) for $\mathrm{CuAR}$; b) for $\mathrm{CuA}$

4.3.2 Simulations with the Lemaitre and Chaboche Damage Model: : The identification of the $S_{0}$ parameter from the corrected density measurements transformed into a Young's modulus evolution following the work of Dufailly [9] gave the value $S_{0}=1.65 \mathrm{MPa}$ for $\mathrm{Cu} 10 \mathrm{AR}$ and 1.4 for $\mathrm{Cu} 10 \mathrm{~A}$. Fig. 6 shows the results of the simulations compared to the experimental curves for the same cases as in 4.3.1. No critical damage value was introduced to induce initiation of cracking : the drop in the curve appears naturally when damage attains a sufficient level. For each triaxiality, the equivalent stress begins to drop when $\mathrm{D}$ attains approximately 0.2 .

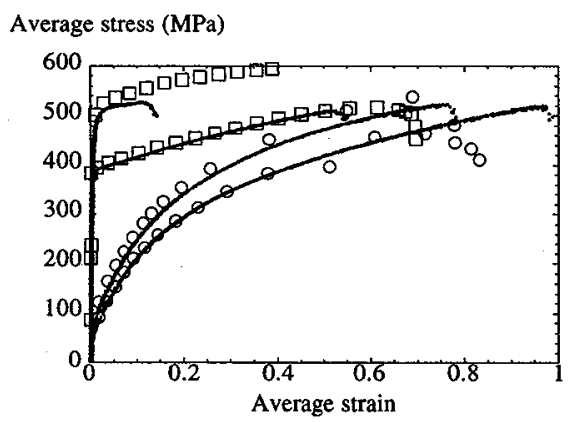

Figure 6 : average stress-average strain curves, experience and elastoplastic finite element simulations with the Lemaître and Chaboche damage model

\section{DISCUSSION AND CONCLUSION}

The correction of the porosity measurements by use of the numerical simulations and of the Rice \& Tracey model allows to derive three interesting conclusions :

(1) The $\alpha$ parameter of the Rice \& Tracey model (equation (2)) is equal to 0.48 . The error in the evaluation of this value has different origins. Equation (11) indicates that the $\alpha$ value is related to the $f_{0}$ value which was measured by metallographic observation. We believe that the error in our measurement of $\mathrm{f}_{0}$ remains lower than $20 \%$. The error in the porosity measurements was evaluated to be not higher than $15 \%$. Finally, the largest error in the evaluation of $\alpha$ comes from the numerics. This last error is difficult to quantify but two considerations can be made : first, the global results are in very good agreement with the experiments; secondly, even if the global results are correct, the triaxiality gradients in the necking section are not necessarily perfectly accurate and a small change in the gradient between the center and the surface of the necked zone can affect considerably the calculation of $\alpha$ because of the presence of the triaxiality ratio in the exponential function (equation (11)). To predict this type of error, 
a more refined numerical.work with a study of convergence will be necessary. We have reevaluated the $\alpha$ values in the extremes cases and found $\alpha=0.48 \pm 0.07$.

A value of $\alpha$ equal to 0.48 is in close agreement with the results of Marini [7] for $f_{0}=0.002$. This value is higher than the value of $\alpha=0.427$ predicted by the Huang model. It is worth stressing that the $\alpha$ value obtained by this procedure is based on a $f_{0}$ value taking into account all inclusions present in the material. However, we are not sure that all the inclusions will bring about the nucleation of a void. Thus the $\alpha$ value obtained by this type of method is a lower bound of the true $\alpha$ value. Nevertheless, we think that a large proportion of the inclusions will give birth to a cavity. The best way to obtain $\alpha$ remains certainly the in-situ observation of the void dimensions. However, in the present case, the cavities are so small (often smaller than $1 \mu \mathrm{m}$ ) and the material is so ductile that polishing methods affect considerably the geometry and the dimensions of the cavities. To our knowledge, no other advanced method is able to detect and measure locally so small voids.

(2) The fact that we obtain, at each step of the finite element results using the corresponding experimental porosity, the same $\alpha$ value is a proof that the porosity measurements and the model used to correct them are consistent with each other. Thus we gain confidence both in our experiments and in the use of the Rice \& Tracey model to describe the porosity evolution.

(3) Using the $\alpha$ value, it is possible to correct the porosity measurements following equation (10) and then to use these measurements to identify the parameters of the Lemaittre \& Chaboche model. The error on the numerical correction does not depend on $f_{0}$ (as it appears when we divide equation (10) by equation (11)) but depends only on the errors in the experimental average porosity measurements and sligthly on the numerical errors. Thus, the relative error on the local porosity values is considerably lower than the relative error on $\alpha$. The true value of the porosity at coalescence is an important feature of the process of fracture. On the basis of physical experiments and reasoning, we obtain $f_{c}=0.02$. It will be interesting to compare this value with the $f_{c}$ value to be used or obtained in a Gurson-Tvergaard type simulation (with or without the use of an ad-hoc function chosen to accelerate softening after coalescence).

Concerning the application of the Rice \& Tracey model (Fig. 3 and 4), we can notice that elastoplastic finite strain modelling (Fig. 3b) allows to simulate the average stress-strain behaviour until initiation and that the equivalent strain at coalescence for a particular triaxiality is the same for CuAR and $\mathrm{CuA}$ (Fig. 4). In addition, the slope of the line passing through the points is very close to the value of 1.5 predicted by the Rice \& Tracey model. This gives support to the two fracture criteria based on this model. The $R_{c} / R_{0}$ values are nearly the same for the two materials and independent on triaxiality. Only the results for specimen CuAR with a notch radius of $1 \mathrm{~mm}(\mathrm{R} 1)$ is lower. The $\mathrm{W}_{\mathrm{dc}}$ values are more constant with respect to triaxiality than the $R_{c} / R_{0}$ values. Finite element simulation of the uniaxial tensile test (without notches) gives also values for $R_{\mathbb{c}} / R_{0}$ close to 2.1 for CuAR and CuA. Analytical evaluation of $R_{c} / R_{0}$ using the triaxiality ratio calculated with the Bridgman model for necking gives values $R_{c} / R_{0}=2.13$ for $C u A R$ and $R_{c} / R_{0}=1.85$ for $C u A$. In conclusion, the two fracture criteria provide transferable critical values in such types of loadings. Future work will study the applicability of these fracture criteria in non-radial loadings and at the tip of a crack.

Concerning the Lemaître \& Chaboche model, the results are not satisfactory for the highest triaxialites but good for lower triaxialities for CuAR whereas the opposite is observed for $\mathrm{CuA}$ (Figure 6). It would have been possible to numerically adjust the parameters of the damage law in such a way as to fit better the experimental curves. However from a physical point of view, we have preferred to proceed from experiments even though the use of the work of Dufailly [9] to transform density measurements in the corresponding Young's modulus evolution may be questionable. The fact that the equivalent stress begins to drop when $\mathrm{D}=0.2$ extends, in finite strain and for copper, an equivalent result found analytically by Doghri $[14,15]$ for steel in small strain.

\section{Acknowledgements}

Part of this work was carried out under financial support of SSTC (Belgium) in the framework of PAI 41. T. Pardoen acknowledges a scholarship of FDS-UCL. The authors are grateful to Professor A. Pineau and Dr R. Chaouadi for fruitful discussion. 


\section{References}

[1] T. Pardoen, F. Delannay, submitted to Int. Journal of Fracture (1996).

[2] F. Mudry, Etude de la rupture ductile et de la rupture par clivage d'aciers faiblement alliés (Thèse d'état, Université de Technologie de Compiègne, 1982).

[3] Beremin, Metallurgical Transactions, 12A (1981) 723-731.

[4] R. Chaouadi, P. De Meester, W. Vandermeulen, Int. Journat of Fracture, 66 (1994) 155-,

[5] J.R. Rice, D.M. Tracey, Journal of the Mechanics and Physics of Solids, 17 (1969) 201-217.

[6] Lemaître, Chaboche, Mécanique des matériaux solides (ed. Dunod., Bordas, Paris, 1985).

[7] B. Marini, F. Mudry, A. Pineau, Engineering Fracture Mechanics, 6 (1985) 989-.

[8] P.W. Bridgman, Studies in large plastic flow and fracture, in Metallurgy and metallurgical engineering series (R.F. Mehl consulting editor, McGraw-Hill Book Company, Inc., 1952).

[9] J. Dufailly, Modélisation mécanique et identification de l'endommagement plastique des métaux (PHD Thesis, Université Pierre et Marie Curie-ENSET, Cachan, France, 1980).

[10] A.L. Helbert, J. Huez, M. Bourgeois, M. Clavel, Etude de la rupture du TA6V, Revue de Metallurgie, SF2M Journees d'Automnes, 9 (1994) 1320 .

[11] Huang, Transactions of the ASME, 58 (1991) 1084

[12] F.A. McClintock, Journal of Applied Mechanics, 35 (1968) 363.

[13] P. Achon, Comportement et Tenacité d'Alliages d'Aluminium à Haute Resistance (PHD Thesis, Ecole Nationale Supérieure des Mines de Paris, 1994).

[14] I. Doghri, R. Billardon, Mechanics of Materials, 19 (1995) 129-149.

[15] I. Doghri, Int. J. Numer. Methods Eng., 38 (1995) 3403-3431.

[16] SPECTRUM Manuals (1994), Centric Engineering Systems, Inc., Santa Clara, California, USA. 